Professor Turner announced that Hyderabad and Oxford were willing to undertake part of the zones originally assigned to Potsdam, provided that the necessary funds for printing could be raised, and a general discussion ensued on the desirability of applying to the Union for funds for this purpose. On the invitation of the President, Professor Ludendorff explained the situation at Potsdam which prevented the resumption of the work by that Observatory.

The following resolution, which was supported by Sir Frank Dyson and Professor Jules Baillaud, was carried unanimously:

"That application be made to the Executive Committee for an annual grant of $£ 300$ until the next meeting of the Union towards the expenses of printing the zones of the Astrographic Catalogue originally assigned to Potsdam and henceforward to be undertaken at Hyderabad and Oxford under circumstances discussed by the Committee at which Professor Ludendorff (Director of the Observatory of Potsdam) was present as a visitor."

\title{
Commission 24. (Parallaxes Stellaires et Mouvements Propres.)
}

Professor S. A. Mitchell presided and Professor Van Rhijn acted as Secretary.

Professor Mitchell referred to the determination of proper motions of Cepheid Stars at the McCormick Observatory.

Professor Van Rhijn spoke about the determination of the proper motions of the selected areas in the northern and southern hemispheres undertaken by the Radcliffe Observatory and the Johannesburg department of the New Haven Observatory respectively.

Professor Mitchell spoke about the determination of proper motions of faint stars at the McCormick Observatory.

Dr Smart and Professor Eddington spoke about the determination of the proper motions of faint stars at the Cambridge Observatory.

Professor Eddington enquired whether somebody could furnish the spectra of the various proper motion stars.

Dr Knox-Shaw moved a recommendation to express proper motions in seconds per year and not in seconds per century. Prof. Russell and Dr Smart opposed this recommendation. It was adopted by 4 votes to 2 .

Dr Lindblad spoke about the spectroscopic parallaxes determined at the Stockholm Observatory and the reconstruction of the Observatory.

Professor Russell spoke about Dr Van Maanen's investigation concerning the systematic errors of parallaxes. Professor Schlesinger, Professor Slocum and Professor Mitchell took part in the discussion.

\section{Commission 25. (Photométrie.)}

In the absence of the President, Professor Seares, the chair was taken by Professor Van Rhijn. Professor B. Lindblad acted as Secretary.

Professor Van Rhijn read a letter from Professor Seares concerning a comparison between the magnitudes of the Potsdam Photometric Durchmusterung for the polar zones $+80^{\circ}$ and $+90^{\circ}$ (Publikationen des Astrophysikalischen Observatoriums zu Potsdam, No. 85, I927) and the Mount Wilson photovisual magnitudes.

The Report was presented for discussion. Professor Vanderlinden communicated some results of a determination of effective wave-lengths of stars in the Selected Areas 40 and $4 \mathrm{r}$. 
Dr Lundmark reported on the determination of effective wave-lengths for extra-galactic nebulae.

Dr Schilt reported on some researches which had given indications of systematic errors in Parkhurst's colour-indices in the Selected Areas of the same kind as those found by Professor Vanderlinden.

Professor Shapley communicated the results of a comparison between Malmquist's colour determinations for stars at the galactic pole and the spectral types determined by Miss Cannon.

Professor Opik drew attention to the importance of determinations of colour for bright red stars.

Professor Vanderlinden read a letter from MM. Grouiller and de Roy recommending a resolution to be made by the Commission concerning the need of a determination of visual sequences of comparison stars for stars in Nijland's List I. The Commission resolved to adopt the resolution.

It was resolved to include the communications referred to above in the Report.

A few slight changes on p. I53 of the Report concerning references to works by Hertzsprung and by Lindblad were made.

Professor Sampson expressed his regret that so little attention had been paid in the Report to the importance of determinations of stellar temperatures by spectrophotometric work.

Professor Shapley replied that in future stellar spectrophotometry was probably to be referred to the activities of Commission 29, which had under consideration to change its name in order to be able to include spectral analysis in general.

\section{Commission 26. (ÉTOILEs Doubles.)}

In the absence of the President of the Commission E. Hertzsprung, acting as Chairman, opened the meeting, July 6, with G. van Biesbroeck as Secretary.

Twenty-five members and guests were present. They were asked to sign their name on a message of greeting sent to the President and also on one to $\mathbf{M r}$ van den Bos at Johannesburg.

The report of the President was read and a number of minor amendments to the text were adopted. The importance of the function of the central bureau was brought out in the course of the discussion. It had been suggested to consider Johannesburg as a centre of information for double stars in the southern hemisphere in the same way as the Lick Observatory had already been for some time in the northern hemisphere. The Commission also approved the request of W. van den Bos that henceforth computers should publish at the same time with the ecliptic elements the constants in the new form that had been worked out at Johannesburg, through which the co-ordinates and radial velocities could be computed very quickly.

Copies of a Catalogue of Orbits so far computed that had been prepared by Dr Luplau-Janssen were distributed.

Mr Fatou was proposed for co-option in the Commission.

\section{Commission 27. (Étolles VARIABLES.)}

Dr Harlow Shapley presided, assisted by Professor A. A. Nijland, Vice-President. Mr Felix de Roy was appointed Secretary and French interpreter; Dr A. Kohlschütter kindly undertook to act as German interpreter. 